\title{
Organic carbon isotopes of planktic foraminifera
}

\author{
BABETTE HOOGAKKER ${ }^{1}$, CAROLINE ANDERSON ${ }^{2}$, \\ HELEN GRANT $^{3}$, CLAIRE MAHAFFEY ${ }^{4}$, SABENA \\ BLACKBIRD $^{4}$, ERIN MCCLYMONT ${ }^{5}$, ROSALIND \\ RICKABY $^{2}$, ALEX POULTON ${ }^{1}$ AND VICTORIA PECK ${ }^{6}$ \\ ${ }^{1}$ Heriot-Watt University \\ ${ }^{2}$ University of Oxford \\ ${ }^{3}$ UK Centre for Ecology and Hydrology \\ ${ }^{4}$ University of Liverpool \\ ${ }^{5}$ Durham University \\ ${ }^{6}$ British Antarctic Survey \\ Presenting Author: b.hoogakker@hw.ac.uk
}

Particulate organic matter (POM) represents an important upper ocean carbon pool that fuels ecosystems. On geological time-scales our understanding of this is limited. Our study exploits the use of planktic foraminifera bound organic carbon isotopes to improve our understanding of the past upper ocean particulate organic carbon pool. Focusing on the Atlantic Ocean we investigate the relationship of bulk sediments and planktic foraminifera bound organic carbon isotopes with that of POM. Our results show that bulk sediment organic carbon isotopes appear to be generally 13C-enriched compared with organic carbon isotopes of POM. Planktic foraminifera bound organic carbon isotopes however appear to be similar to organic carbon isotopes of POM, confirming earlier work suggesting there is no appreciable fractionation between the organic carbon isotopes of heterotrophic plankton and their autotrophic prey. Thus, planktic foraminifera bound organic carbon isotopes offer an exciting route to study past variations in organic carbon isotopes of POM and to improved understanding of the carbon cycle over geological time-scales. 